
Enhanced Electrochemical Performance

SUBJECT AREAS:

BATTERIES

ELECTRONIC MATERIALS

NANOWIRES

CHEMICAL PHYSICS

Received

3 April 2013

Accepted

30 May 2013

Published

18 June 2013

Correspondence and requests for materials should be addressed to G.Z.S. Igzshen@semi. ac.cn) or D.C. (dichen@mail.hust. edu.cn) \title{
for Lithium-lon Batteries
}

\author{
Xianfu Wang', Qingyi Xiang' ', Bin Liu', Lijing Wang', Tao Luo', Di Chen' \& Guozhen Shen²
}

\begin{abstract}
'Wuhan National Laboratory for Optoelectronics (WNLO), and School of Optical and Electronic Information, Huazhong University of Science and Technology (HUST), Wuhan, 430074, P. R. China, ${ }^{2}$ State Key Laboratory for Superlattices and Microstructures, Institution of Semiconductors, Chinese Academy of Science, Beiijing, 100083 P. R. China.
\end{abstract}

Anatase $\mathrm{TiO}_{2}$ modified $\mathrm{FeS}$ nanowires assembled by numerous nanosheets were synthesized by using a typical hydrothermal method. The carbon-free nanocoated composite electrodes exhibit improved reversible capacity of $510 \mathrm{mAh} \mathrm{g}^{-1}$ after 100 discharge/charge cycles at $200 \mathrm{~mA} \mathrm{~g}^{-1}$, much higher than that of the pristine $\mathrm{FeS}$ nanostructures, and long-term cycling stability with little performance degradation even after 500 discharge/charge cycles at current density of $400 \mathrm{~mA} \mathrm{~g}^{-1}$. Full batteries fabricated using the FeS@ $\mathrm{TiO}_{2}$ nanostructures anode and the $\mathrm{LiMn}_{2} \mathrm{O}_{4}$ nanowires cathode with excellent stability, and good rate capacities could also be achieved. The enhanced electrochemical performance of the composite electrodes can be attributed to the improved conductively of the integrated electrodes and the enhanced kinetics of lithium insertion/extraction at the electrode/electrolyte interface because of the incorporation of anatase $\mathrm{TiO}_{2}$ phase.

ithium-ion batteries, one of the most promising energy-storage devices and providing the power for almost all current portable electronics, have attracted worldwide attention accompanying the increasing concerns about the limited global energy supply and the degradation of living environment ${ }^{1-6}$. The performances of lithium-ion batteries depend largely on the properties and structures of electrode materials for lithium storage ${ }^{7,8}$. Two-dimensional (2D) nanostructures are of great interest in lithium storage due to their shortened paths for fast lithium ion diffusion and large exposed surface offering more lithium-insertion channels ${ }^{9,10} .2 \mathrm{D}$ nanostructures of some layered-structured metal sulfides, such as $\mathrm{WS}_{2}$, and $\mathrm{MoS}_{2}$ have been actively studied as electrode materials in lithium-ion batteries due to their structural advantages in reversible Li storage processes ${ }^{11-14}$. However, the metal elements in these sulfides are relatively heavy, which may limit their theoretical specific energies densities ${ }^{10}$.

Iron sulfides are interesting materials for energy storage applications due to their cost effectiveness and abundance in nature. Furthermore, they have a higher Li-insertion voltage (ca. $1.3 \mathrm{~V} \mathrm{vs} \mathrm{Li} / \mathrm{Li}$ ) than that of commercial graphite anode (below $0.2 \mathrm{~V} \mathrm{vs} \mathrm{Li}^{+} / \mathrm{Li}$ ), which can avoid reduction of electrolyte on the surface of the electrode and formation of the solid-electrolyte interphase (SEI) layer (usually occurring below $1.0 \mathrm{~V} \mathrm{vs} \mathrm{Li}^{+} / \mathrm{Li}$ ). Several kinds of iron sulfides have been studied as electrodes for lithium-ion batteries, which storage Li via a conversion reaction ${ }^{15,16}$. However, the products after the discharge process in such batteries are insulating polysulfides $\left(\mathrm{Li}_{2} \mathrm{~S}_{x}, 1<x<8\right)$, which could easily dissolve in liquid electrolyte ${ }^{16}$. Besides losing active material, the dissolved polysulfides also deteriorate the conductivity of the electrolyte and the electrode leading to capacity degradation ${ }^{17-19}$. What's more, part of the insulating reaction products cover the electrode and prevent its further electrochemical reactions. Recently, carbon-based capping the sulfides into thin wrapping layers is a successful strategy to reduce polysulfides dissolution into the electrolyte. However, because of safety issues concerning carbon materials, great efforts are also directed to carbon-free coatings for achieving superior rate performance, high tap density, and surface stability ${ }^{20}$. At this stage, a novel iron sulfides nanostructures with 2D morphology for lithium ion transport and uniform carbon-free conducting nanocoating layer are still highly desired.

Herein, we successfully exhibit a novel one-dimensional anatase $\mathrm{TiO}_{2}$ modified $\mathrm{FeS}$ nanostructure composed of $2 \mathrm{D}$ graphene-like FeS nanosheets via a facile hydrothermal growth method followed with the treatment in $\mathrm{TiCl}_{4}$ solution. As expected, the $\mathrm{TiO}_{2}$ modified $\mathrm{FeS}$ nanostructure displayed excellent Li storage properties with considerable capacity of $520 \mathrm{mAh} \mathrm{g}^{-1}$ after 100 discharge/charge cycles at $200 \mathrm{~mA} \mathrm{~g}^{-1}$, superior cyclic stability (456 $\mathrm{mAh} \mathrm{g}^{-1}$ even after 500 discharge/charge cycles at $400 \mathrm{~mA} \mathrm{~g}^{-1}$ ) and improved rate capability compared with those of the pure FeS nanostructures. The enhanced electrochemical performances of the composite electrodes 


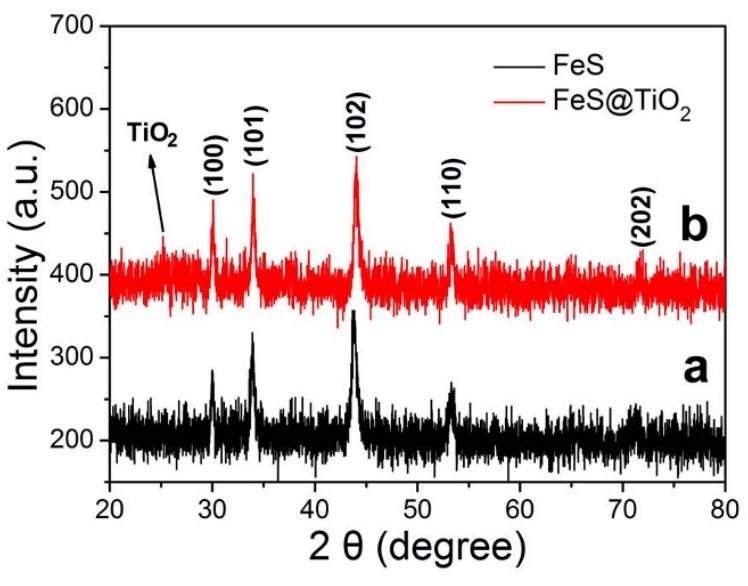

Figure $1 \mid$ XRD patterns of the as-synthesized FeS and $\mathrm{FeS} @ \mathrm{TiO}_{2}$ nanostructures.

can be attributed to the large exposed electrochemical active surface, the improvement of lithium diffusion coefficient, and the electrical conductivity of the overall electrode because of the introduction of anatase $\mathrm{TiO}_{2}$ phase, which were confirmed by the investigation of the lithium storage performance, electrochemical impedance and the kinetics of lithium ion insertion/extraction.

\section{Results}

The FeS@ $\mathrm{TiO}_{2}$ nanostructures were synthesized via a facile hydrothermal method combined with a post-treatment process. Figure 1 shows the X-ray diffraction (XRD) patterns of the FeS products before and after $\mathrm{TiO}_{2}$ treatment. All peaks in Figure 1a can be well indexed as hexagonal FeS (JCPDS Card No. 03-065-3356, space group P-62c). As for the FeS@ $\mathrm{TiO}_{2}$ sample shown in Figure 1b, all the diffraction peaks of $\mathrm{FeS}$ remain unchanged, while the peak located at $25.2^{\circ}$ matches well with the (101) plane of anatase $\mathrm{TiO}_{2}$ (JCPDS Card No. 01-065-9124), indicating the formation of anatase $\mathrm{TiO}_{2}$. The morphology and microstructures of the as-prepared products were characterized by field-emission scanning electron microscopy (FE-SEM) as illustrated in Figure 2. One-dimensional (1D) wire-like materials with lengthes of tens of micrometers on a large scale can be obtained for the $\mathrm{FeS} @ \mathrm{TiO}_{2}$ nanostructures (Figure 2a). Further observation of the SEM image in Figure 2b, we can clearly see that the wire-like nanostructures were assembled by numerous 2D nanosheets, being in sharp contrast with the smooth surface of the precursor before calcination (Figure S1), while keeping well with the pure FeS nanostructures (Figure S2), due to the running away of organics in the precursor. The corresponding energydispersive X-ray spectroscopy (EDS) (Figure 2c) suggests the existence of $\mathrm{Fe}, \mathrm{S}, \mathrm{Ti}$ and $\mathrm{O}$ in the resultant $\mathrm{FeS} @ \mathrm{TiO}_{2}$ nanostructures, further confirm the introduction of $\mathrm{TiO}_{2}$, in good agreement with the $\mathrm{XRD}$ result. In the spectrum, the peak of Pt comes from the deposited platinum when prepared for SEM characterization. The corresponding elemental mapping of $\mathrm{Fe}, \mathrm{S}, \mathrm{Ti}$ and $\mathrm{O}$ in the $\mathrm{FeS}_{\mathrm{TiO}}$ nanostructures is shown in Figure S3, revealing the uniform dispersion of those elements. Besides, the EDS pattern and the corresponding elemental mapping of $\mathrm{Fe}$ and $\mathrm{S}$ in the pure $\mathrm{FeS}$ nanostructures are also depicted in Figure S4 and S5.

Typical TEM image of an individual $\mathrm{FeS} @ \mathrm{TiO}_{2}$ nanostructure was shown in Figure 2d, where a lot of nanosheets assemble into the 1D composite nanostructure can be seen. Further observation of the nanosheet (Figure S6) revealed that $\mathrm{TiO}_{2}$ nanoparticles were implanted on the surface of FeS nanosheet. Figures $2 \mathrm{e}$ and $2 \mathrm{f}$ show the high-resolution TEM (HRTEM) images of the FeS nanosheet and $\mathrm{TiO}_{2}$ nanoparticle in the composite nanosheets. The well-resolved periodic lattice fringe with an interplanar distance of $0.48 \mathrm{~nm}$ comes from the (101) plane of hexagonal FeS (Figure 2e). Two sets of lattice fringes with inter-plane spacing of 0.24 and $0.35 \mathrm{~nm}$ indicated in the HRTEM image (Figure 2f) are attributed to the (004) and (101) planes of the anatase $\mathrm{TiO}_{2}$ phase, respectively.

For the formation of FeS nanosheets, it is believed that the annealing temperature plays an important role in determining their final shapes. Previously, people reported that nanowires were obtained once the annealing temperature was set at $200-300^{\circ} \mathrm{C}^{21}$. While in our case, we increased the annealing temperature to $500^{\circ} \mathrm{C}$ and nanosheets assembled nanostructures were thus obtained. At a higher temperature, combined with the evaporation the organics from the precursors, the rapid diffusion process of the atoms may
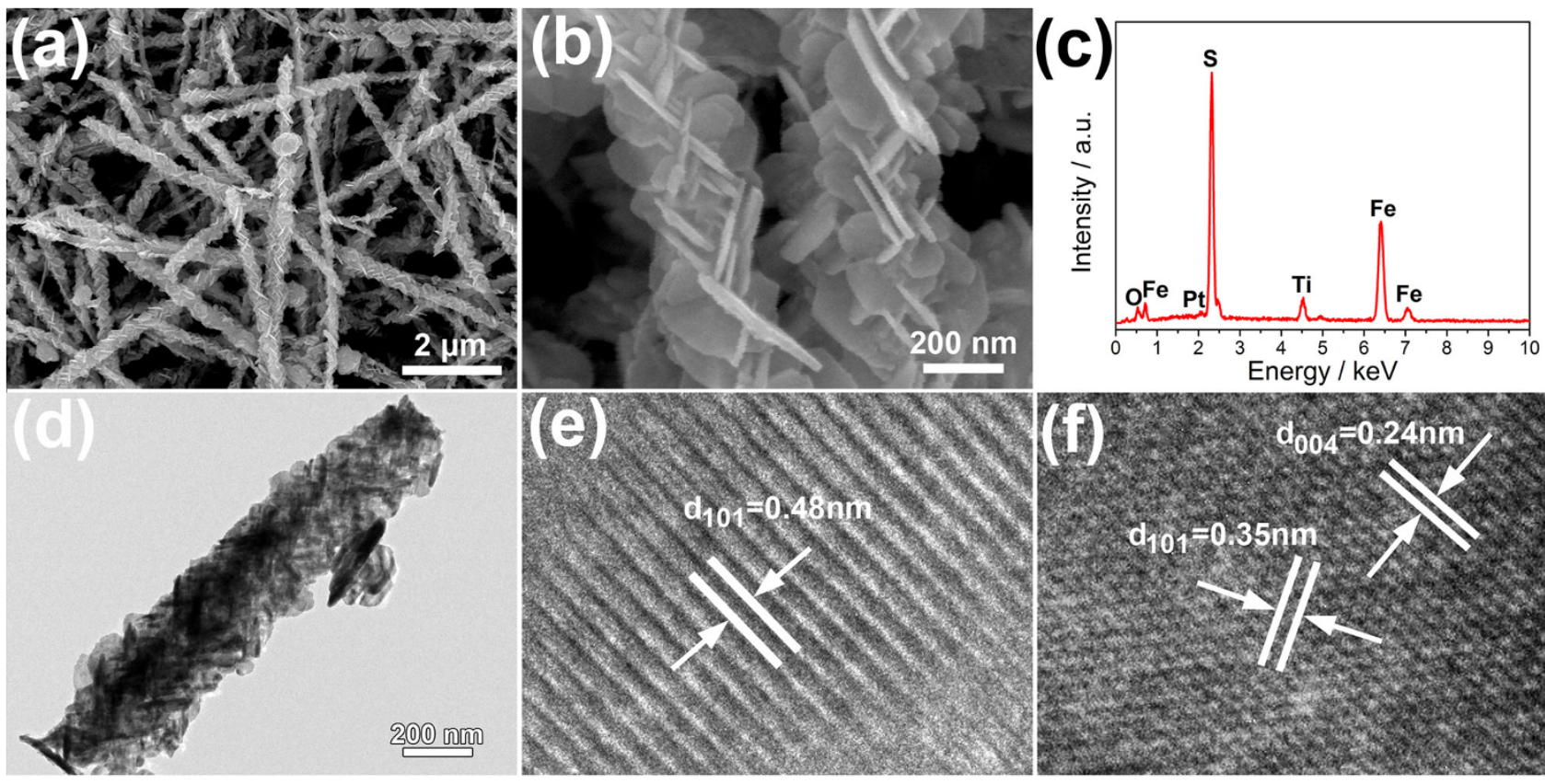

Figure $2 \mid(a, b)$ SEM images, (c) EDS pattern, (d) TEM image and (e, f) HRTEM images of the as-prepared FeS@TiO ${ }_{2}$ nanostructures. 

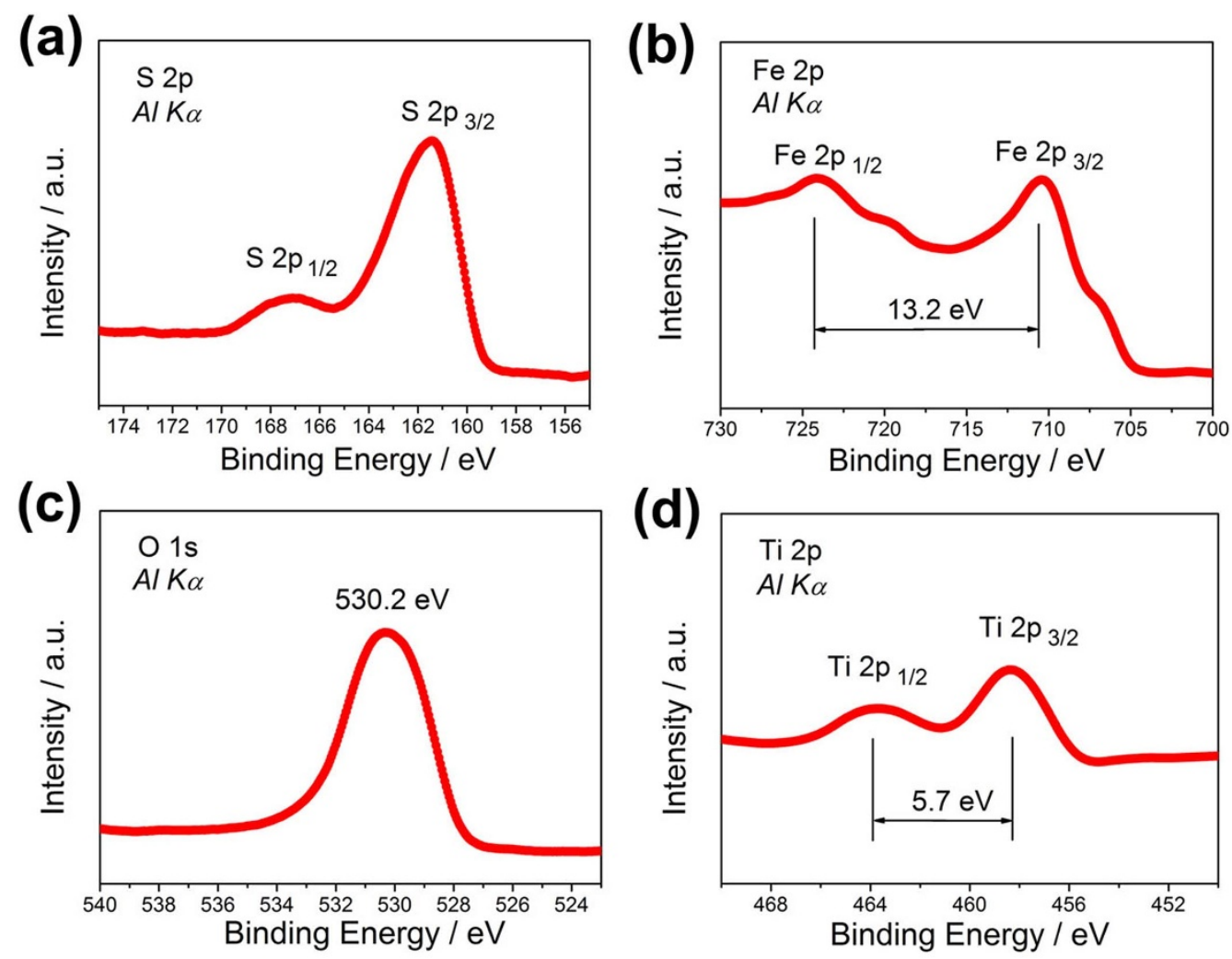

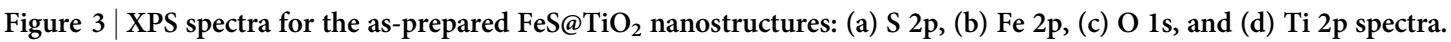

take place across the interface (the amorphous layers, grain boundaries, and so on) to allow the formation of the hexagonal FeS nanosheets ${ }^{10}$, which may be attributed to the confined growth within the (001) plane of the hexagonal symmetrical crystals ${ }^{22,23}$. With the reaction went along, the novel nanostructures assembled by nanosheets were collected.

X-ray photoelectron spectroscopy (XPS) was employed to analyze the information on the surface chemical compositions and the valence states of the FeS@ $\mathrm{TiO}_{2}$ nanostructures. Figure 3a shows the XPS spectrum of the S 2p core-level. Two signals at 161.5 and $167.5 \mathrm{eV}$ can be attributed to $S 2 p_{3 / 2}$ and $S 2 p_{1 / 2}$, respectively, characteristic peaks of FeS. The core level spectra of Fe $2 \mathrm{p}$ are shown in Figure $3 \mathrm{~b}$. Peaks corresponding to $708.4 \mathrm{eV}$ and $721.6 \mathrm{eV}$ are attributed to $\mathrm{Fe}^{2+}$ states coming from FeS phase, whereas $710.5 \mathrm{eV}$ and $723.4 \mathrm{eV}$ are ascribed to $\mathrm{Fe}^{3+}$ states, which may be attributed to the $\mathrm{Fe}^{3+}$ formed from iron and oxide elements. The peak of $\mathrm{O} 1 \mathrm{~s}$ (Figure $3 \mathrm{c}$ ) is centered at $530.2 \mathrm{eV}$, which is attributed to the $\mathrm{O}^{2+}$ forming oxide with titanium. Fig. $3 \mathrm{~d}$ presents the XPS spectra of Ti $2 \mathrm{p}$ doublet peaks. The binding energy of $\mathrm{Ti} 2 \mathrm{p}_{1 / 2}$ and $\mathrm{Ti} 2 \mathrm{p}_{3 / 2}$ was observed at approximately $464.2 \mathrm{eV}$ and $458.5 \mathrm{eV}$, respectively. The splitting data between the Ti $2 \mathrm{p}_{1 / 2}$ and $\mathrm{Ti} 2 \mathrm{p}_{3 / 2}$ core levels are $5.7 \mathrm{eV}$, indicating a normal state of $\mathrm{Ti}^{4+}$ in the anatase $\mathrm{TiO}_{2}{ }^{24}$. These results indicate that anatase $\mathrm{TiO}_{2}$ phase have been introduced successfully into the FeS nanostructures.

To demonstrate the effect of the introduced anatase $\mathrm{TiO}_{2}$ in improving the lithium storage performance, we investigate the electrochemical properties of the pristine $\mathrm{FeS}$ and $\mathrm{FeS} @ \mathrm{TiO}_{2}$ nanostructures as anode materials for lithium batteries, respectively. Figures $4 \mathrm{a}$ and $4 \mathrm{~b}$ show the discharge/charge voltage profiles of the $\mathrm{FeS}$ and $\mathrm{FeS} @ \mathrm{TiO}_{2}$ nanostructures electrodes at a current density of $200 \mathrm{~mA} \mathrm{~g}^{-1}$ between 0.01 and $3.0 \mathrm{~V}$ versus $\mathrm{Li}^{+} / \mathrm{Li}$ for the first cycle, respectively. A quite distinct plateau at $1.25 \mathrm{~V}$ is observed, which is caused by a reaction between iron sulfides and lithium with the formation of $\mathrm{Fe}$, and $\mathrm{Li}_{2-}{ }_{\mathrm{x}} \mathrm{FeS}_{2}$ phases depending on the quantity of lithium transfer per pyrrhotite ${ }^{25}$. Another plateau exists between 0.8 and $0.2 \mathrm{~V}$, which is mainly attributed to the formation of $\mathrm{Li}_{2} \mathrm{FeS}_{2}$ and the solid electrolyte interface (SEI) layer on the electrode surface $^{26}$. The FeS and FeS@ $\mathrm{TiO}_{2}$ nanostructures electrodes deliver large initial discharge capacity of 900 and $920 \mathrm{mAh} \mathrm{g}^{-1}$ during the first cycle, which may be attributed to the form of SEI layer and the irreversible reaction between $\mathrm{Li}$ and $\mathrm{FeS}$ as indicated in the following reactions:

$$
\begin{gathered}
2 \mathrm{FeS}+2 \mathrm{Li}^{+}+2 \mathrm{e}^{-}=\mathrm{Li}_{2} \mathrm{FeS}_{2}+\mathrm{Fe} \\
\mathrm{FeS}+2 \mathrm{Li}^{+}+2 \mathrm{e}^{-}=\mathrm{Li}_{2} \mathrm{~S}+\mathrm{Fe}
\end{gathered}
$$

In the charge profiles, voltage slopes can be observed at 1.9-2.0 V, which is associated with the oxidation process of $\mathrm{Fe}$ to $\mathrm{Li}_{2} \mathrm{FeS}_{2}{ }^{27}$. No significant differences of the voltage profiles indicate that the reaction between the introduced $\mathrm{TiO}_{2}$ and lithium is too feeble to contribute to the total capacity of $\mathrm{FeS} @ \mathrm{TiO}_{2}$ electrode.

Stable cyclic performance of electrode materials is important for practical application of lithium-ion batteries. The discharge/charge cycling stability of the FeS and $\mathrm{FeS} @ \mathrm{TiO}_{2}$ nanostructures electrodes were examined at a current density of $200 \mathrm{~mA} \mathrm{~g}^{-1}$ between 0.01 and 3.0 V. As evidenced in Figure 4c, the composite electrode shows considerable enhanced discharge/charge capacity with respect to

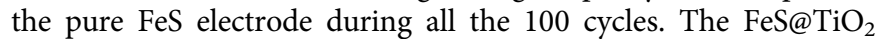
nanostructures electrode exhibits a discharge capacity of $505 \mathrm{mAh}$ $\mathrm{g}^{-1}$ during the 15 th cycle and remains at $510 \mathrm{mAh} \mathrm{g}^{-1}$ after 100 cycles, which are much higher than those of the pure FeS electrode (320, and $266 \mathrm{mAh} \mathrm{g}^{-1}$ during the 15 th and after 100 cycles, respect-

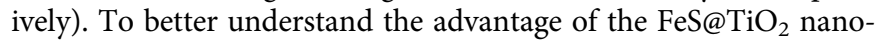

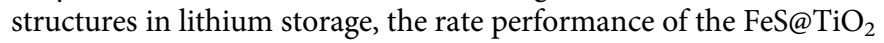
nanostructures electrode is also investigated (Figure 4d). Obviously, compared with the pristine FeS electrode, the specific capacities of the composite electrode are substantially increased at all investigated discharge/charge rates from 100 to $4000 \mathrm{~mA} \mathrm{~g}^{-1}$. It depicts that the 

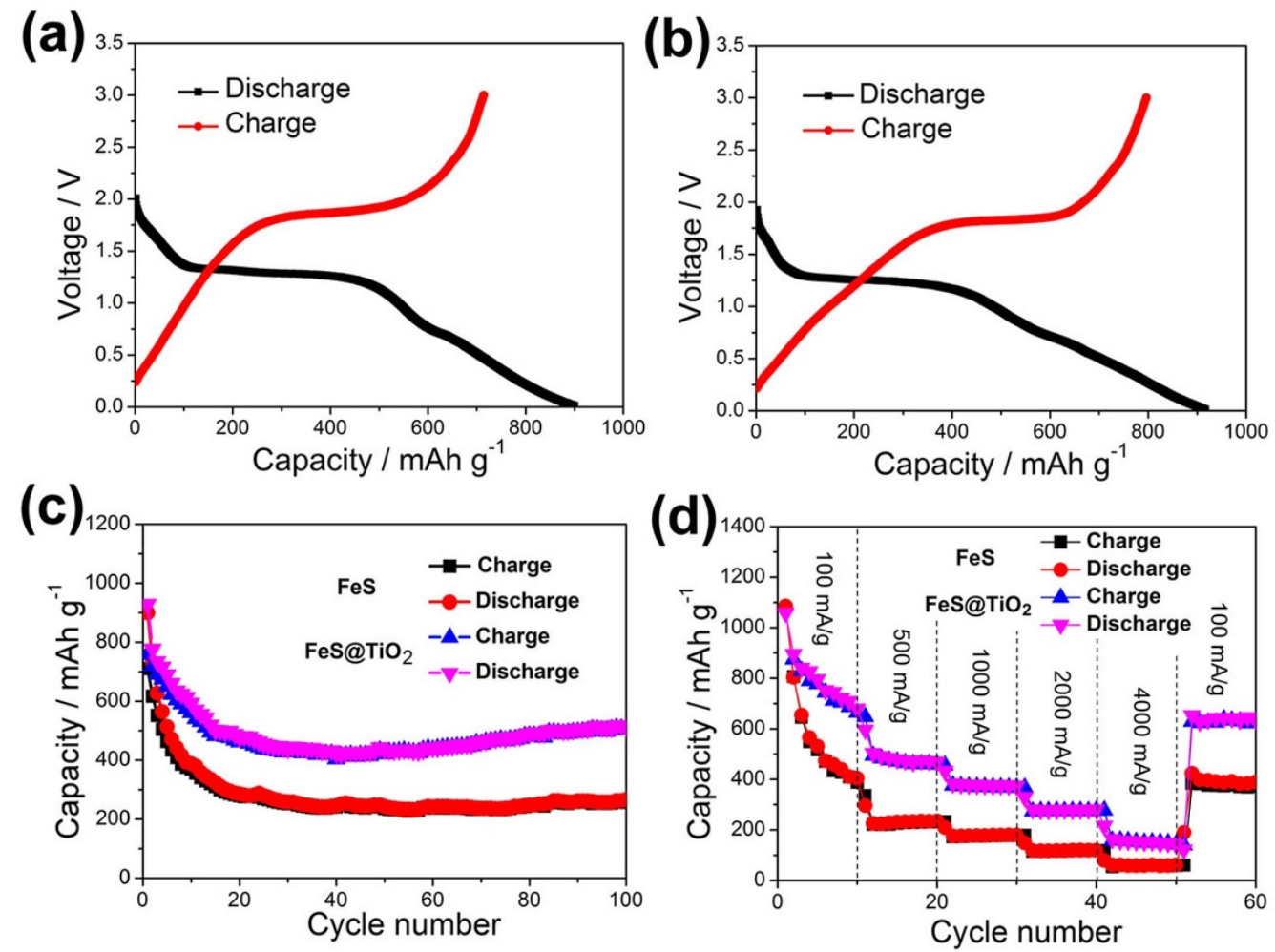

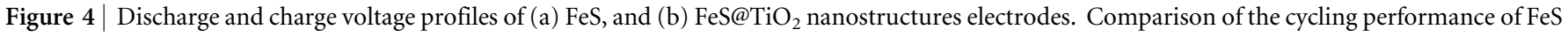
and $\mathrm{FeS} @ \mathrm{TiO}_{2}$ nanostructures electrodes: (c) at $200 \mathrm{~mA} \mathrm{~g}^{-1}$, and (d) at various current densities of 100, 500, 1000, 2000, and 4000 mA g ${ }^{-1}$.

ninth cycle discharge capacities are around $705,474,382,283$, and $160 \mathrm{mAh} \mathrm{g}^{-1}$ at current densities of 100, 500, 1000, 2000, and $4000 \mathrm{~mA} \mathrm{~g}^{-1}$, respectively, which are about two times larger than those of the pristine FeS electrode $(407,235,179,121$, and $60 \mathrm{mAh}$ $\left.\mathrm{g}^{-1}\right)$. These results reveal that the incorporation of anatase $\mathrm{TiO}_{2}$ into FeS nanostructures can greatly enhance the electrochemical performance for lithium storage.

To get more information about the electrochemical properties of the FeS@ $\mathrm{TiO}_{2}$ nanostructures electrode, the cyclic performance was also carried out at current densities of 100,400 , and $800 \mathrm{~mA} \mathrm{~g}^{-1}$ as revealed in Figure $5 \mathrm{a}$. When tested at a low current density of $100 \mathrm{~mA} \mathrm{~g}^{-1}$, the capacity of the composite electrode is as high as $635 \mathrm{mAh} \mathrm{g}^{-1}$ after 100 discharge/charge cycles, much higher than that of the C@FeS nanoplates electrode ${ }^{10}$. Importantly, the $\mathrm{FeS} @ \mathrm{TiO}_{2}$ nanostructures electrode still exhibits an excellent cyclic performance at much higher current densities of 400 and $800 \mathrm{~mA} \mathrm{~g}^{-1}$, and the capacities reach 440 and $355 \mathrm{mAh} \mathrm{g}^{-1}$ after 100 discharge/charge cycles. The corresponding coulombic efficiencies of the electrode cycled at 100 to $800 \mathrm{~mA} \mathrm{~g}^{-1}$ were shown in Figure 5b. The coulombic efficiencies (nearly 100\%) are still highly expected for the composite electrode, though different discharge/charge current densities are applied, further demonstrating the excellent lithium storage performance of the $\mathrm{FeS} @ \mathrm{TiO}_{2}$ nanostructures electrode. Furthermore, the composite electrode exhibits satisfactory cycling performance as evidenced in Figure $5 \mathrm{c}$ and $5 \mathrm{~d}$. The specific capacity of the composite is $430 \mathrm{mAh} \mathrm{g}^{-1}$ after 500 discharge/charge cycles at $400 \mathrm{~mA} \mathrm{~g}^{-1}$ with a coulombic efficiency of $99 \%$, demonstrating the high cyclic stability and good reversibility of the $\mathrm{FeS} @ \mathrm{TiO}_{2}$ nanostructures electrode.

To explore the potential application of the $\mathrm{FeS} @ \mathrm{TiO}_{2}$ nanostructures as the anode material of full battery, spinel $\mathrm{LiMn}_{2} \mathrm{O}_{4}$ nanowires were synthesized and selected as the cathode material because of its three-dimensional tunnel structure for the migration of lithium ions and advantage of fast charging resulted from the stable delithiated structure ${ }^{28}$. All peaks in the XRD pattern of the as-synthesized $\mathrm{LiMn}_{2} \mathrm{O}_{4}$ nanowires (Figure S7) can be well indexed as spinel $\mathrm{LiMn}_{2} \mathrm{O}_{4}$ (JCPDS Card No. 01-089-8325). Figure S8 shows the SEM image of the as-synthesized $\mathrm{LiMn}_{2} \mathrm{O}_{4}$ nanowires with uniform diameter of $200 \mathrm{~nm}$ and length of $10 \mathrm{um}$. The electrochemical performances of the as-prepared $\mathrm{LiMn}_{2} \mathrm{O}_{4}$ nanowires were first evaluated as demonstrated in Figures $6 \mathrm{a}$ and $6 \mathrm{~b}$. The $\mathrm{LiMn}_{2} \mathrm{O}_{4}$ nanowires electrode exhibits impressive specific capacities $\left(82-94 \mathrm{mAh} \mathrm{g}^{-1}\right.$ at $\left.500 \mathrm{~mA} \mathrm{~g}^{-1}\right)$, high coulombic efficiency of $99 \%$, and excellent cycling performance with capacity retention more than $87 \%$ after 100 charge/discharge cycles. Galvanostatic charge-discharge curves of the half cell based on the $\mathrm{LiMn}_{2} \mathrm{O}_{4}$ nanowires electrode (Figure S9) display expected discharge plateau potentials of 4.05 and $3.9 \mathrm{~V}$ at $500 \mathrm{~mA} \mathrm{~g}^{-1}$, in according with the previous report ${ }^{28}$. As can be seen in Figure $6 b$, the cathode shows capacities of $89,85,78,70$, and $62 \mathrm{mAh} \mathrm{g}^{-1}$ at current densities ranged from 100 to $2000 \mathrm{~mA} \mathrm{~g}^{-1}$. The little capacity loss with the increase of the charge/discharge current densities indicates the superior rate capability of the $\mathrm{LiMn}_{2} \mathrm{O}_{4}$ nanowires.

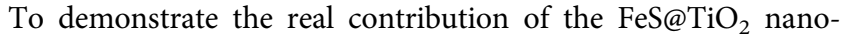
structures electrode to the assembled $\mathrm{LiMn}_{2} \mathrm{O}_{4} / \mathrm{FeS} @ \mathrm{TiO}_{2}$ full battery, the over-capacity of the $\mathrm{LiMn}_{2} \mathrm{O}_{4}$ nanowires was adopted. Figure $6 \mathrm{c}$ shows the charge/discharge voltage profiles of the asfabricated full battery. As expected from the operating voltages of the FeS@ $\mathrm{TiO}_{2}$ nanostructures and $\mathrm{LiMn}_{2} \mathrm{O}_{4}$ nanowires, their combination produces a battery with an operating voltage of $2.2 \mathrm{~V}$, and the discharge capacity of the battery is $520 \mathrm{mAh} \mathrm{g}^{-1}$ with a coulombic efficiency of $98 \%$ at $200 \mathrm{~mA} \mathrm{~g}^{-1}$. The rate performance of the full battery was further inspected, as illustrated in Figure 6d. Remarkably, an acceptable capacity of 350 and $170 \mathrm{mAh} \mathrm{g}^{-1}$ at 500 and $1500 \mathrm{~mA}$ $\mathrm{g}^{-1}$, respectively, during the 5 th cycle could be achieved, which are comparable with the rate performance of practical graphite-based full battery, although the rate capacity at high current density is still 
(a)

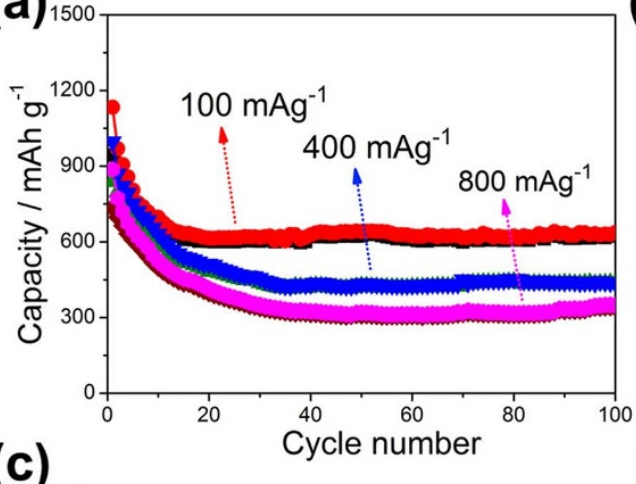

(c)

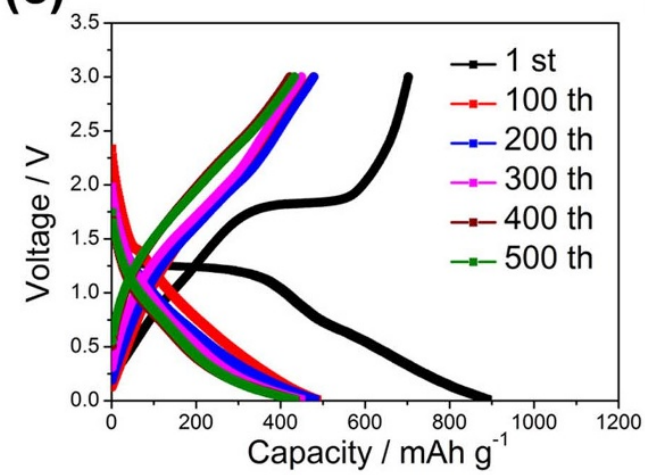

(b)

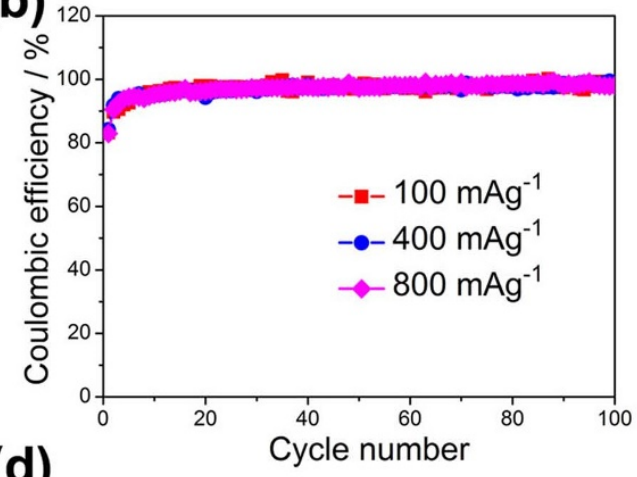

(d)

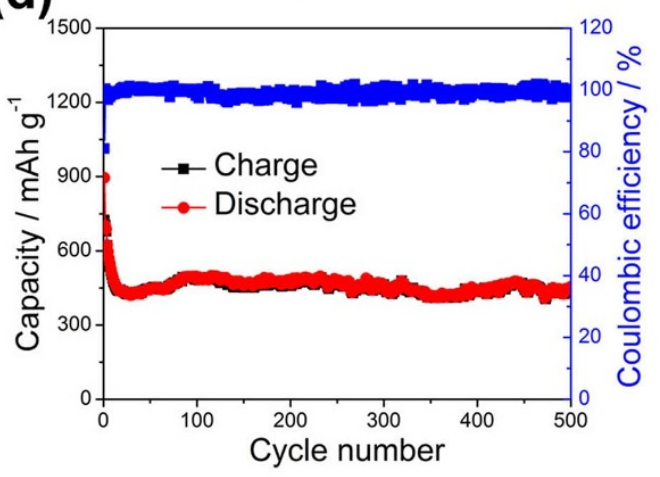

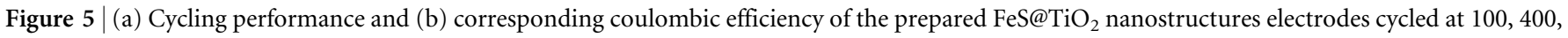
and $800 \mathrm{~mA} \mathrm{~g}^{-1}$. (c) Discharge and charge voltage profiles and (d) long cycling performance of the electrode at a current density of $400 \mathrm{~mA} \mathrm{~g}^{-1}$.

(a)

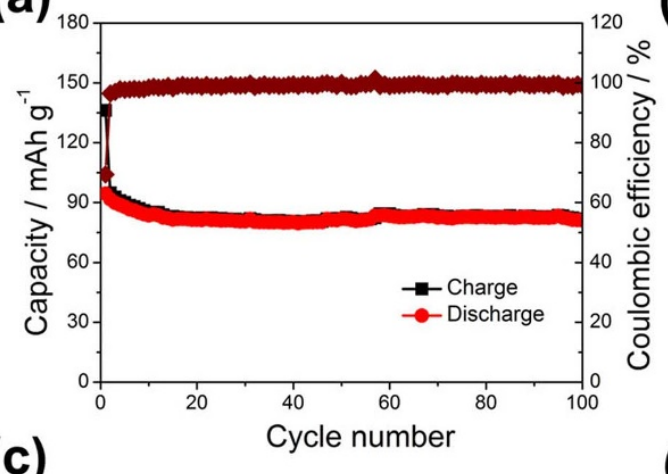

(c)

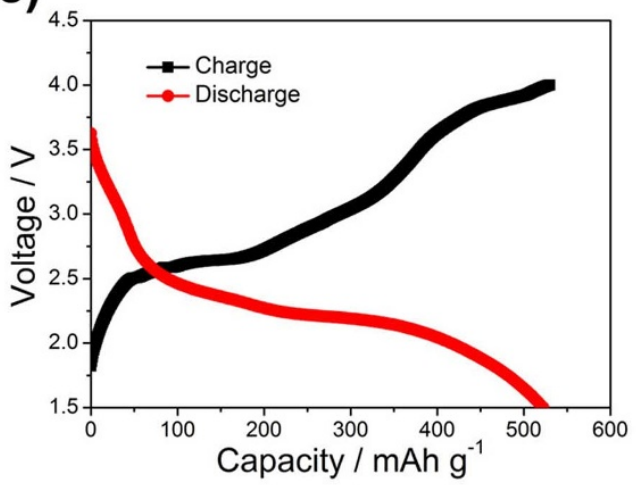

(b)

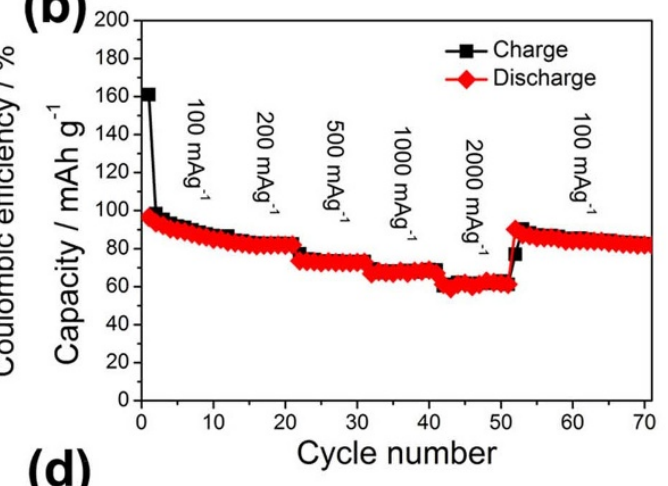

(d)

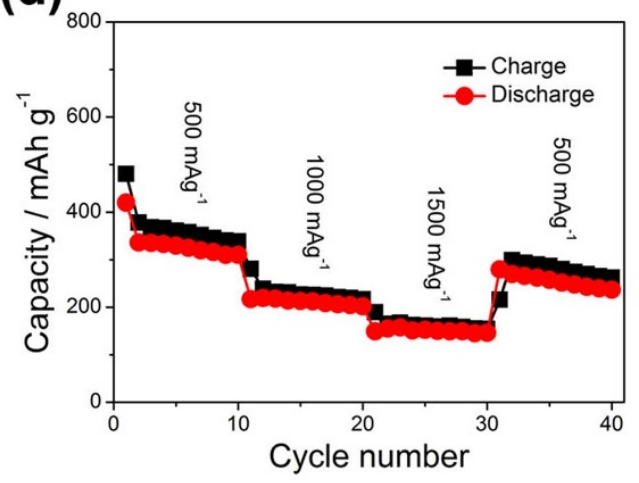

Figure 6 Cycling performance of the as-synthesized $\mathrm{LiMn}_{2} \mathrm{O}_{4}$ nanowires electrodes at (a) $500 \mathrm{~mA} \mathrm{~g}^{-1}$, and (b) various current densities ranged from 100 to $2000 \mathrm{~mA} \mathrm{~g}^{-1}$. (c) Charge and discharge voltage profiles at $200 \mathrm{~mA} \mathrm{~g}^{-1}$ and (d) rate performance at current densities between 500 and

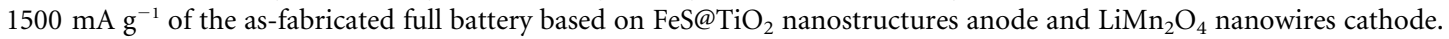



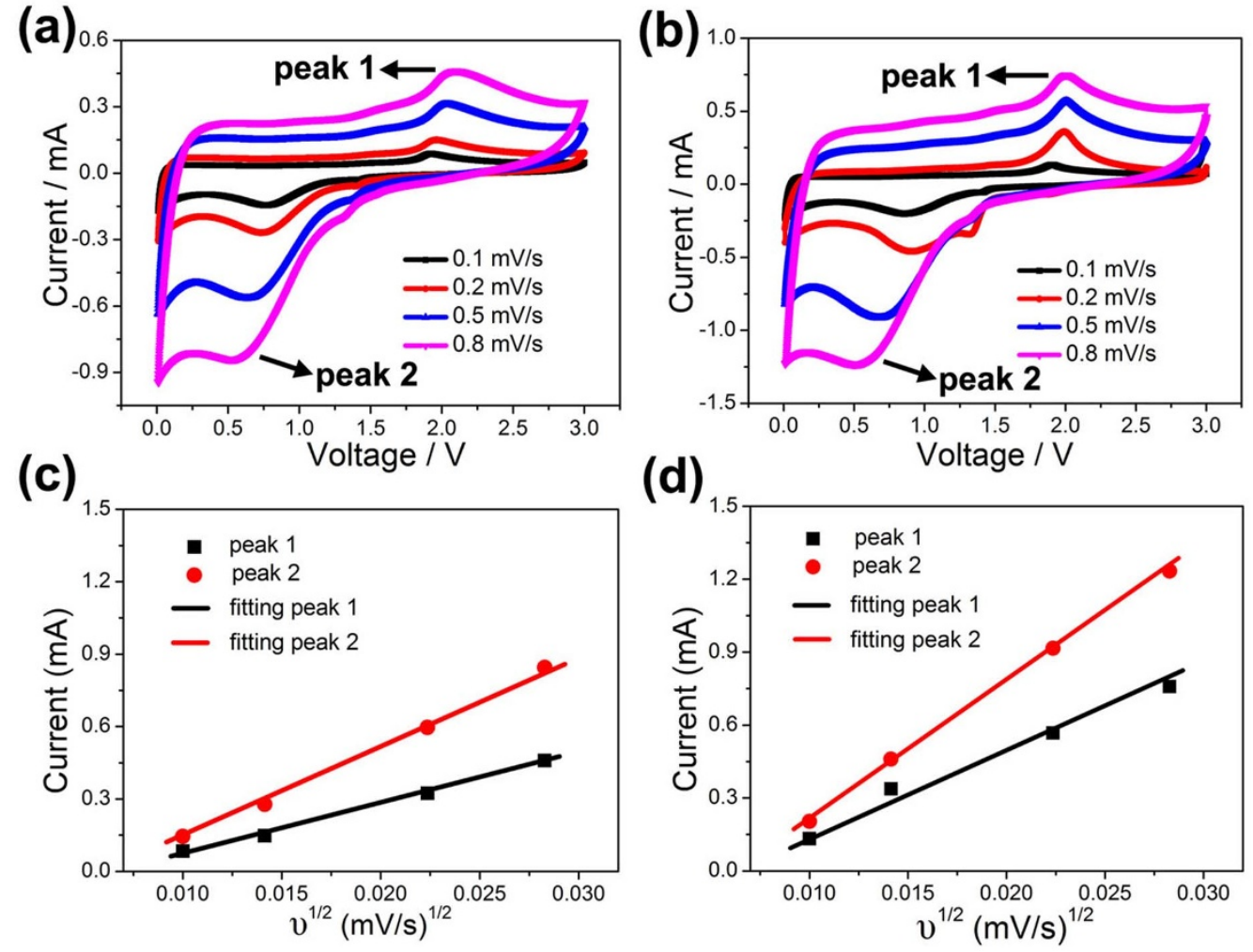

(d)

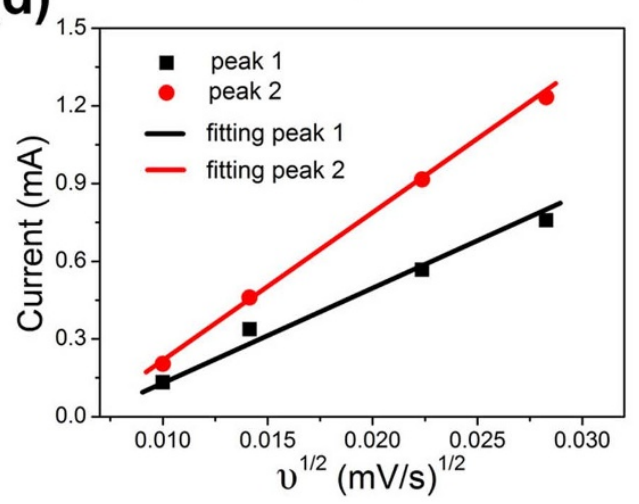

Figure $7 \mid \mathrm{CV}$ curves and peak currents versus square root of scan rates of $(\mathrm{a}, \mathrm{c})$ the $\mathrm{FeS}$, and $(\mathrm{b}, \mathrm{d}) \mathrm{FeS} @ \mathrm{TiO}_{2}$ nanostructures electrodes scanned at 0.1 , $0.2,0.5$, and $0.8 \mathrm{mV} \mathrm{s}^{-1}$ after 5th, 10th, 15th, and 20th cycles.

need to be improved. Further investigations are on-going to improve the capacity of the full cell at high discharge rates to meet the demand of electronic device for high energy density.

\section{Discussion}

In order to gain better understanding on the enhanced electrochemical performances of the $\mathrm{FeS} @ \mathrm{TiO}_{2}$ nanostructures electrodes, we have performed $\mathrm{CV}$ measurements to investigate the kinetics of lithium ion insertion/extraction at the electrode/electrolyte interface and rate of lithium diffusion in the film. It is known that the change in peak shape with sweep rate reflects the kinetics of lithium insertion/ extraction at the electrode/electrolyte interface and rate of lithium diffusion in the film ${ }^{29}$. Figures $7 \mathrm{a}$ and $7 \mathrm{~b}$ show the $\mathrm{CV}$ curves of the

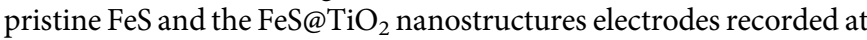
scan rates of $0.1-0.8 \mathrm{mV} \mathrm{s}^{-1}$ in the voltage range of $0.01-3.0 \mathrm{~V}$ after 5 th, 10 th, 15 th, and 20 th cycles. As the scan rates increase, the cathodic and anodic peaks moved to lower and higher potential, respectively, with the increase of the magnitude of the peak currents.

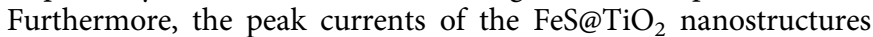
electrodes are higher than those of the pristine FeS electrodes, indicating the incorporation of $\mathrm{TiO}_{2}$ render the composite electrodes much faster lithium diffusion and much higher lithium storage capacity. As evidenced in Figures $7 \mathrm{c}$ and $7 \mathrm{~d}$, linear correlation was established between the anodic/cathodic peak currents and the square roots of scan rates for both Peak 1 and 2, which suggests diffusionlimited reactions $s^{30}$. In this kind of reaction, the peak currents and scan rates follow the Randles-Sevcik equation ${ }^{31}$ :

$$
I_{p}=\left(2.69 \times 10^{5}\right) n^{3 / 2} A D^{1 / 2} v^{1 / 2} \Delta C_{0}
$$

Where $I_{p}$ is the peak current; $n$ is the number of transfer electrons; A is the surface area of electrodes; $\mathrm{D}$ is the diffusion coefficient; $v$ is the scan rate, and $\Delta \mathrm{C}_{0}$ is the concentration of reaction. It is worth noting that the slops for peak 1 and peak 2 on the $\mathrm{FeS@TiO} 2$ nanostructures were higher than those for the FeS system, revealing that the combination of $\mathrm{TiO}_{2}$ into the $\mathrm{FeS}$ nanostructures is benefit to improve the lithium diffusion coefficient, resulting the enhanced electrochemical performance for lithium storage.

To gain insight into the prominent electrochemical properties of the $\mathrm{FeS} @ \mathrm{TiO}_{2}$ nanostructures with respect to the FeS electrode, we also take the electrochemical impedance spectroscopy (EIS) measurements as shown in Figure 8. The equivalent circuit model of the studied system is also shown in Figure 8 inset to represent the internal resistance of the test battery according to literature ${ }^{32,33}$. The high-frequency semicircle corresponds to the contact resistance $\left(R_{f}\right)$ and constant phase element of the SEI film (CPE1), the semicircle in the medium-frequency region is assigned to the charge-transfer impedance $\left(\mathrm{R}_{\mathrm{ct}}\right)$ and constant phase element of electrode/electrolyte

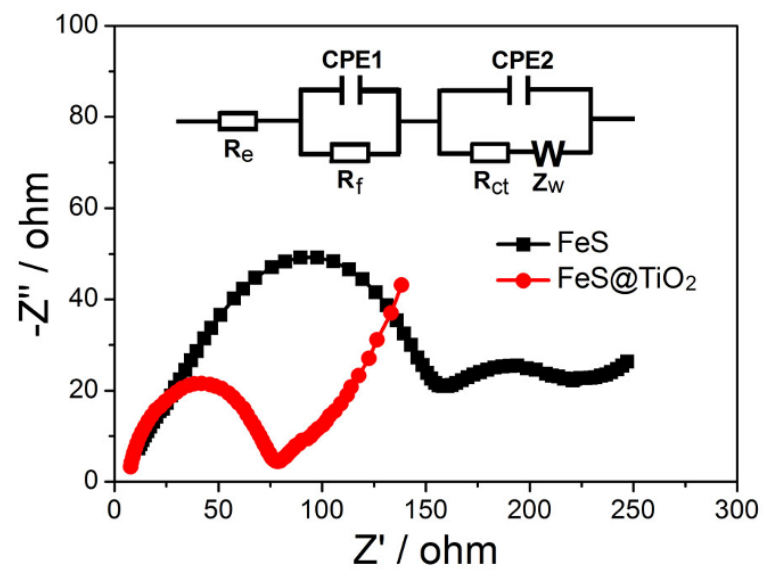

Figure 8 Electrochemical impedance spectra of $\mathrm{FeS}$ and $\mathrm{FeS} @ \mathrm{TiO}_{2}$ nanostructures electrodes obtained by applying a sine wave with amplitude of $5.0 \mathrm{mV}$ over the frequency range from $100 \mathrm{kHz}$ to $0.1 \mathrm{~Hz}$. 
Table 1 Impedance parameters derived using equivalent circuit model for $\mathrm{FeS}$ and $\mathrm{FeS} @ \mathrm{TiO}_{2}$ nanostructures electrodes

\begin{tabular}{lccl} 
electrodes & $\mathrm{R}_{\mathrm{e}}(\Omega)$ & $\mathrm{R}_{\mathrm{f}}(\Omega)$ & $\mathrm{R}_{\mathrm{ct}}(\Omega)$ \\
\hline $\mathrm{FeS}$ & 8.9 & 140.2 & 169.7 \\
$\mathrm{FeS} @ \mathrm{TiO}_{2}$ & 5.8 & 84.9 & 109 \\
\hline
\end{tabular}

interface (CPE2), and $\mathrm{Z}_{\mathrm{w}}$ is associated with the Warburg impedance corresponding to the lithium-diffusion process. Clearly, the diameter of the semicircle for the $\mathrm{FeS} @ \mathrm{TiO}_{2}$ nanostructures electrode in the high-medium frequency regain is much smaller than that of the pristine $\mathrm{FeS}$ electrode, revealing that the $\mathrm{FeS} @ \mathrm{TiO}_{2}$ nanostructures electrode possess lower contact and charge-transfer impedances. This result also validates that the introduced $\mathrm{TiO}_{2}$ can improve the electrical conductivity of the overall electrode. Besides, from the low frequency inclined line, we can find that the lithium-diffusion process of the $\mathrm{FeS} @ \mathrm{TiO}_{2}$ nanostructures electrode is much easier than that of the FeS electrode, further conforming that the coated $\mathrm{TiO}_{2}$ benefit the lithium-diffusion of the composite electrode. The kinetic differences of $\mathrm{FeS}$ and $\mathrm{FeS} @ \mathrm{TiO}_{2}$ electrodes were further investigated by modeling AC impedence spectra based on the modified equivalent circuit ${ }^{34,35}$. The fitted impedence parameters are listed in Table 1. It can be seen that the SEI film resistance $\mathrm{R}_{\mathrm{f}}$ and charge-transfer resistance $\mathrm{R}_{\mathrm{ct}}$ of the $\mathrm{FeS} @ \mathrm{TiO}_{2}$ electrode are $84.9 \Omega$ and $109 \Omega$, which are significantly lower than those of the pristine FeS (140.2 $\Omega$ and $169.7 \Omega$ ). This fact once again confirms that the introduction of $\mathrm{TiO}_{2}$ can preserve the high conductivity of the $\mathrm{FeS} @ \mathrm{TiO}_{2}$ composite electrode and greatly enhance rapid electron transport during the electrochemical lithium insertion/extraction reaction, resulting in significant improvement in the electrochemical performances.

In summary, we exhibited a novel one-dimensional anatase $\mathrm{TiO}_{2}$ modified FeS nanostructure composed of $2 \mathrm{D}$ FeS nanosheets and $\mathrm{TiO}_{2}$ nanoparticles. The composite electrodes show a capacity of $510 \mathrm{mAh} \mathrm{g}^{-1}$ after 100 cycles, much higher than that of the pristine FeS nanostructures $\left(266 \mathrm{mAh} \mathrm{g}^{-1}\right)$ at a current density of $200 \mathrm{~mA}$ $\mathrm{g}^{-1}$. Meanwhile, the integrated electrodes exhibit enhanced rate capability at current densities ranged from 100 to $4000 \mathrm{~mA} \mathrm{~g}^{-1}$ and long-term cycling stability with little performance degradation even after 500 discharge/charge cycles at current density of $400 \mathrm{~mA} \mathrm{~g}^{-1}$. The superior electrochemical performances of the composite nanostructures can be ascribed to the incorporation of anatase $\mathrm{TiO}_{2}$, which, to some extent, improve the conductively of the integrated electrodes and enhance the kinetics of lithium insertion/extraction at the electrode/electrolyte interface and rate of lithium diffusion in the film. The carbon-free conducting nanocoated electrodes would open up new opportunities in the development of high performance nextgeneration lithium-ion batteries and other energy conversion and storage devices used for alternative and sustainable energy.

\section{Methods}

Preparation of $\mathrm{FeS}$ and $\mathrm{FeS} @ \mathrm{TiO}_{2}$ nanostructures. FeS nanostructures were prepared by using solvothermal method, similar to the literature except the anneal temperature ${ }^{21}$. Briefly, $\mathrm{FeCl}_{2} \cdot 4 \mathrm{H}_{2} \mathrm{O}(1.18 \mathrm{~g})$ was mixed with $\mathrm{CH}_{3} \mathrm{CSNH}_{2}$ (thioacetamide, $0.9 \mathrm{~g}$ ) in Teflon-lined steel autoclave and $40 \mathrm{~mL}$ ethylenediamine was add to it. The container was sealed and heated to $180^{\circ} \mathrm{C}$ for 4 days under solvothermal conditions to obtain organic-inorganic composite nanowires. FeS nanostructures were obtained by annealing the composite products at $500^{\circ} \mathrm{C}$ for 60 min under a flow of $\mathrm{N}_{2}(200 \mathrm{sccm})$. To obtain $\mathrm{FeS} @ \mathrm{TiO}_{2}$ nanostructures, the composite products were first immersed in the $\mathrm{TiCl}_{4}$ solution $(40 \mathrm{mM})$ at $70^{\circ} \mathrm{C}$ for $30 \mathrm{~min}$, and then annealed at $500^{\circ} \mathrm{C}$ for $60 \mathrm{~min}$ under a flow of $\mathrm{N}_{2}(200 \mathrm{sccm})$.

Fabrication of $\mathrm{LiMn}_{2} \mathrm{O}_{4}$ nanowires. $\mathrm{LiMn}_{2} \mathrm{O}_{4}$ nanowires were fabricated via a solid state reaction of $\beta-\mathrm{MnO}_{2}$ nanowires and lithium hydroxide. The synthesis of $\beta-\mathrm{MnO}_{2}$ nanowires can be seen in our previous report ${ }^{36}$. Typically, manganese sulfate $(0.338 \mathrm{~g})$ and potassium chlorate $(0.246 \mathrm{~g})$ were dissolved in $25 \mathrm{~mL}$ of distilled water under vigorous stirring to form a homogeneous solution. The mixture was then transferred to a Teflon-lined stainless steel autoclave and kept in an oven at $200^{\circ} \mathrm{C}$ for $12 \mathrm{~h}$. After being treated, the obtained $\beta-\mathrm{MnO}_{2}$ nanowires were collected and then mixed with lithium hydroxide with mole ratio of $1: 0.55$. After annealing at $750^{\circ} \mathrm{C}$ for $10 \mathrm{~h}$ in air, the $\mathrm{LiMn}_{2} \mathrm{O}_{4}$ nanowires were obtained.

Charactization. The phase purity of the products were characterized by X-ray powder diffraction (XRD) using an X-Ray diffractometer with $\mathrm{Cu} \mathrm{K} \alpha$ radiation $(\lambda=$ $0.15 \mathrm{~nm}$ ). Scanning electron microscopy (SEM) images and energy dispersive X-Ray spectroscopy (EDS) analyses were obtained using a Sirion 200 microscope. Transmission electron microscopy (TEM) and high-resolution TEM (HRTEM) observations were carried out on a Philips CM 200 instrument. X-Ray photoelectron spectroscopy (XPS) spectra were performed on a VG Multilab 2000 system with a monochromatic aluminium anode $\mathrm{X}$-ray source.

Electrochemical evaluation. The working electrodes were fabricated by coating a slurry containing 70 wt\% active materials ( $\mathrm{FeS}$ or $\mathrm{FeS} @ \mathrm{TiO}_{2}$ nanostructures), 20 wt\% acetylene black (Super-P), and $10 \mathrm{wt} \%$ polyvinylidene fluoride (PVDF) dissolved in $\mathrm{N}$-methyl-2-pyrrolidinone onto a copper foil and dried at $80^{\circ} \mathrm{C}$ in vacuum for $12 \mathrm{~h}$ before pressing. Laboratory-made two-electrode CR2032 coin cells were assembled in an argon-filled glovebox using a pure lithium foil as the counter electrode. A separator membrane (Celgard 2300) was used to isolate the two electrodes. The electrolyte was $1 \mathrm{M} \mathrm{LiPF}_{6}$ dissolved in a mixture of ethylene carbonate (EC) and dimethyl carbonate $(\mathrm{DMC})(\mathrm{v} / \mathrm{v}=1: 1)$. The coin cells were galvanostatically discharged/charged at different current densities between 0.01 and $3.00 \mathrm{~V}\left(v s . \mathrm{Li}^{+} / \mathrm{Li}\right)$ by using a battery testing system (LAND, China). Cyclic voltammetry (CV) was measured on an electrochemical workstation (CHI 760D, CH Instruments Inc., Shanghai) and electrochemical impedance spectrometry in the frequency range of $100 \mathrm{kHz}$ to $0.1 \mathrm{~Hz}$ at room temperature.

1. Arico, A. S., Bruce, P. G., Scrosati, B., Tarascon, J. \& Schalkwijk, W. V. Nanostructured materials for advanced energy conversion and storage devices. Nat. Mater. 4, 366-377 (2005).

2. Guo, Y.-G., Hu, J.-S. \& Wan, L.-J. Nanostructured Materials for Electrochemical Energy Conversion and Storage Devices. Adv. Mater. 20, 2878-2887 (2008).

3. Wang, H. et al. Graphene-wrapped sulfur particles as a rechargeable lithiumsulfur battery cathode material with high capacity and cycling stability. Nano Lett. 11, 2644-2647 (2011).

4. Lee, S., Cho, Y., Song, H.-K., Lee, K. T. \& Cho, J. Carbon-coated single-crystal $\mathrm{LiMn}_{2} \mathrm{O}_{4}$ nanoparticle clusters as cathode material for high-energy and highpower lithium-ion batteries. Angew. Chem. Int. Ed. 51, 8748-8752 (2012).

5. Singh, N. et al. Paintable battery. Sci. Rep. 2, 481 (2012).

6. Ding, S., Chen, J. S. \& Lou, X. W. One-Dimensional Hierarchical Structures Composed of Novel Metal Oxide Nanosheets on a Carbon Nanotube Backbone and Their Lithium-Storage Properties. Adv. Funct. Mater. 21, 4120-4125 (2011)

7. Wang, H. G., Ma, D. L., Huang, X. L., Huang, Y. \& Zhang, X. B. General and controllable synthesis strategy of metal oxide/ $/ \mathrm{TiO}_{2}$ hierarchical heterostructures with improved lithium-ion battery performance. Sci. Rep. 2, 481 (2012).

8. Wang, X. F. et al. Three-dimensional hierarchical $\mathrm{GeSe}_{2}$ nanostructures for high performance flexible all-solid-state supercapacitors. Adv. Mater. 25, 1479-1486 (2013).

9. Liu, J. \& Liu, X.-W. Two-dimensional nanoarchitectures for lithium storage. $A d v$. Mater. 24, 4097-4111 (2012).

10. Xu, C. et al. Controlled soft-template synthesis of ultrathin C@FeS nanosheets with high-Li-storage performance. ACS Nano 6(6), 4713-4721 (2012).

11. Liu, H., Su, D. W., Wang, G. X. \& Qiao, S. Z. An ordered mesoporous $W_{2}$ anode material with superior electrochemical performance for lithium ion batteries. J. Mater. Chem. 22, 17437-17440 (2012).

12. Yang, L. et al. Hierarchical $\mathrm{MoS}_{2} /$ polyaniline nanowires with excellent electrochemical performance for lithium-ion batteries. Adv. Mater. 25, 1180-1184 (2013).

13. Xiao, J. et al. Electrochemically induced high capacity displacement reaction of PEO/MoS 2 /graphene nanocomposites with lithium. Adv. Funct. Mater. 21, 2840-2846 (2011).

14. Ji, L., Lin, Z., Alcoutlabi, M. \& Zhang, X. Recent developments in nanostructured anode materials for rechargeable lithium-ion batteries. Energy Environ. Sci. 4, 2682-2699 (2011).

15. Kostov, S. et al. X-ray absorption fine structure studies of FeS cathodes in lithium polymer electrolyte batteries. Journal of Power Sources 81-82, 709-714 (1999).

16. Kim, Y. \& Goodenough, J. B. Lithium insertion into transition-metal monosulfides: tuning the position of the metal $4 \mathrm{~s}$ band. J. Phys. Chem. C 112, 15060-15064 (2008).

17. Cheon, S. E. et al. Rechargeable litium sulphur battery II. Rate capacity and cycle characteristics. J. Electrochem. Soc. 150, A800-A805 (2003).

18. Ji, L. et al. Graphene oxide as a sulfur immobilizer in high performance lithium/ sulfur cells. J. Am. Chem. Soc. 133, 18522-18525 (2011).

19. Ji, L. et al. Porous carbon nanofiber-sulfur composite electrodes for lithium/sulfur cells. Energy Environ. Sci. 4, 5053-5059 (2011).

20. Wang, Y.-Q. et al. Rutile- $\mathrm{TiO}_{2}$ nanocoating for a high-rate $\mathrm{li}_{2} \mathrm{Ti}_{5} \mathrm{O}_{12}$ anode of lithium-ion battery. J. Am. Chem. Soc. 134, 7874-7879 (2012).

21. Nath, M., Choudhury, A., Kundu, A. \& Rao, C. N. R. Synthesis and characterization of magnetic iron sulfide nanowires. Adv. Mater. 15, 2098-2101 (2003). 
22. Wang, W. Z. et al. High-yield synthesis of single-crystalline antimony telluride hexagonal nanoplates using a solvothermal approach. J. Am. Chem. Soc. 127, 13792-13793 (2005).

23. Saadat, S. et al. Template-free electrochemical deposition of interconnected $\mathrm{ZnSb}$ nanoflakes for li-ion battery anodes. Chem. Mater. 23, 1032-1038 (2011).

24. Luo, Y. S. et al. Seed-assisted synthesis of highly ordered $\mathrm{TiO}_{2} @ \mathrm{Fe}_{2} \mathrm{O}_{3}$ core/shell arrays on carbon textiles for lithium-ion battery applications. Energy Environ. Sci. 5, 6559-6566 (2012).

25. Yang, S. H. \& Quinn, C. H. Chemical, structural and electrochemical comparison of natural and synthetic $\mathrm{FeS}_{2}$ pyrite in lithium cells. Electrochim. Acta. 46, 2613-2621 (2001)

26. Wu, B., Song, H., Zhou, J. S. \& Chen, X. H. Iron sulphide-embedded carbon microsphere anode material with high-rate performance for lithium-ion batteries. Chem. Commun. 47, 8653-8655 (2011).

27. Fong, R., Jones, C. H. W. \& Dahn, J. R. A study of pyrite-based cathodes for ambient temperature lithium batteries by in situ Fe Mossbauer spectroscopy. J. Power Sources, 26, 333-339 (1989).

28. Hosono, E., Kudo, T., Honma, I., Matsuda, H. \& Zhou, H. S. Synthesis of single crystalline spine $\mathrm{LiMn}_{2} \mathrm{O}_{4}$ nanowires for a lithium ion battery with high power density. Nano Lett. 9(3), 1045-1051 (2009).

29. Rougier, A., Striebel, K. A., Wen, S. J. \& Cairns, E. J. Cyclic voltammetry of pulsed laser deposited $\mathrm{Li}_{\mathrm{x}} \mathrm{Mn}_{2} \mathrm{O}_{4}$ thin films. J. Electrochem. Soc. 145, 2975-2980 (1998).

30. Zhang, B. et al. Exceptional electrochemical performance of freestanding electrospun carbon nanofiber anodes containing ultrafine $\mathrm{SnO}_{\mathrm{x}}$ particles. Energy Environ. Sci. 5, 9895-9902 (2012).

31. Das, S. R., Majumder, S. B. \& Katiyar, R. S. Kinetic analysis of the $\mathrm{Li}^{+}$ion intercalation behavior of solution derived nano-crystalline lithium manganite thin films. J. Power Sources. 139, 261-268 (2005).

32. Yang, S., Feng, X., Ivanovici, S. \& Müllen, K. Fabrication of Grapheneencapsulated oxide nanoparticles: towards high-performance anode materials for lithium storage. Angew. Chem., Int. Ed. 49, 8408-8411 (2010).

33. Chang, K. \& Chen, W. X. L-Cysteine-assisted synthesis of layered $\mathrm{MoS}_{2}$ /graphene composites with excellent electrochemical performances for lithium ion batteries. ACS Nano 28, 4720-4728 (2011).

34. Yang, S. B. et al. Nanographene-constructed hollow carbon spheres and their favorable electroactivity with respect to lithium storage. Adv. Mater. 22, 838-842 (2010).
35. Yang, S. B., Song, H. H. \& Chen, X. H. Electrochemical performance of expanded mesocarbon microbeads as anode material for lithium-ion batteries. Electrochem. Commun. 8, 137-142 (2006).

36. Wang, L. J. et al. Facile synthesis and electrochemical properties of $\mathrm{CoMn}_{2} \mathrm{O}_{4}$ anodes for high capacity lithium-ion batteries. J. Mater. Chem. A 1, 2139-2143 (2013)

\section{Acknowledgments}

We acknowledge the support from the National Natural Science Foundation (21001046 $51002059,91123008)$, the 973 Program of China (2011CB933300) and the Program for New Century Excellent Talents of the University in China (grant no. NCET-11-0179). We thank the Analytical and Testing Center of Huazhong University Science \& Technology and the Center of Micro-Fabrication and Characterization (CMFC) of WNLO for the samples measurements.

\section{Author contributions}

X.F.W., D.C. and G.Z.S. devised the original concept, designed the experiment, discussed the interpretation of results and co-wrote the paper. X.F.W., Q.Y.X. and L.J.W. performed the experiments. B.L. and T.L. analysed the dates. All authors reviewed the manuscript.

\section{Additional information}

Supplementary information accompanies this paper at http://www.nature.com/ scientificreports

Competing financial interests: The authors declare no competing financial interests.

How to cite this article: Wang, X.F. et al. $\mathrm{TiO}_{2}$ modified FeS Nanostructures with Enhanced Electrochemical Performance for Lithium-Ion Batteries. Sci. Rep. 3, 2007; DOI:10.1038/ srep02007 (2013)

(c) (i) $($ ) $\Theta$ This work is licensed under a Creative Commons Attribution-

cc) ${ }_{\mathrm{BY}} \mathrm{Nc}$ ND NonCommercial-NoDerivs Works 3.0 Unported license. To view a copy of this license, visit http://creativecommons.org/licenses/by-nc-nd/3.0 